\title{
Numerical Simulation of Hydraulic Jump over Rough Beds
}

\author{
Saman Nikmehr ${ }^{1 *}$, Younes Aminpour \\ 1 Department of Water Science and Engineering, University of Kurdistan, Kurdistan Province, Pasdaran Blvd. Sanandaj, P.O.B. \\ 66177-15175, Iran \\ 2 Department of Hydraulic Structures, Water Research Institute, Ministry of Energy, Tehran, Iran \\ * Corresponding author, e-mail: s.nikmehr@uok.ac.ir
}

Received: 15 November 2019, Accepted: 24 February 2020, Published online: 16 March 2020

\begin{abstract}
In this study, the hydraulic jumps over rough beds are numerically simulated. In order to calibrate the numerical model, the experimental data were used, which performed in a rectangular flume in various roughness arrangements and different Froude numbers. The effect of the distance $(s)$ and the height $(t)$ of the roughness on different characteristics of the hydraulic jump, including the sequent depth ratio, water surface profile, jump's length, roller's length, and velocity distribution were evaluated and compared. The results showed that the numerical model is fairly well able to simulate the hydraulic jump characteristics. The results also showed that the height and distance of roughness slightly reduced the sequent depth ratios for all Froude numbers. Also, the hydraulic jump length is reduced at the presence of the rough bed. Velocity profiles in different experiments were similar and there was a good agreement between simulated and measured results. Also, increasing the distance and the height of the roughness will slow down the velocity near the bed, increase the shear stress, and increase the gradient of the velocity distribution near the bed.
\end{abstract}

Keywords

hydraulic jump, numerical simulation, rough beds, FLOW 3D Model

\section{Introduction}

Hydraulic jump is defined as the sudden transition from a supercritical flow to subcritical condition in a short distance. Furthermore, the hydraulic jump is a phenomenon where the water surface moves upwards through critical depth as kinetic energy is converted to potential energy $[1,2]$. Hydraulic jumps are usually used to dissipate excessive energy downstream of the hydraulic structures. Hydraulic jumps on smooth beds have been extensively investigated [3-11]. In these beds, considering the depth and initial flow velocity, and using existing mathematical and empirical relationships, the sequent depth ratio and length of hydraulic jump can be determined.

Until now, many experimental studies have been carried out on the hydraulic jump over a rough bed [12-15]. Rajaratnam [12] is one of the pioneers who widely studied the characteristics of the hydraulic jump on rough bed channels. He introduced the parameter $k=k_{e} / y_{1}$ representing the effect of bed roughness on the lengths of rollers zone $\left(L_{r}\right)$ and length of hydraulic jump $\left(L_{j}\right)$, in which $k_{e}$ is the equivalent height of bed roughness and $y_{1}$ is the depth of incoming supercritical flow. Hughes and Flack [13] showed that the boundary roughness decreases the sequent depth and length of hydraulic jump depending on Froude number of incoming flow and relative height of bed roughness. Mohamed [16] used square cross strips and observed 17.4 to $67.4 \%$ decrease on the lengths of hydraulic jump when the Froude number of incoming flow was varied from 4 to 10. Ead et al. [17] reported that the sequent depth of hydraulic jump on corrugated beds is less than that on smooth beds where the lengths of hydraulic jump decreases with $50 \%$ and shear stress increases by 10 times. Tokyay [18] investigated the effect of channel bed corrugations on a hydraulic jump experimentally. In the experiments 2 values of wave steepness, 0.20 and 0.26 , were used and the range of Froude numbers was from 5 to 12 . The results showed that many factors, such as initial flow depth, supercritical Froude number, height, and wave length of corrugations were effective on the characteristics of the hydraulic jump. Izadjoo and Shafai Bejestan [19] showed that the sequent depths of the hydraulic jump on corrugated beds is $20 \%$ less than that on smooth beds. They reported that the length of hydraulic jump on trapezoidal corrugated beds may decrease by $50 \%$ which is mostly the consequences of roughness crest than the openings. They also concluded 
that the shear stress increases by 10 times compared to classic hydraulic jump. Ead and Elsebaie [20] used three sinusoidal, trapezoidal and triangular corrugated rough beds and found that the shape of rough elements dose not play an important role on $y_{2} / y_{1}$. Carollo and Ferro [21] studied the characteristics of hydraulic jump on a rip-raped bed and concluded that relative sequent depth $y_{2} / y_{1}$ decreases with the size of bed roughness. Hassanpour et al. [22] investigated the effect of geometric and hydraulic parameters on energy dissipation and location of the hydraulic jump, in different roughness heights and the divergence of walls. Their results showed that the tail-water depth, the roller length, and the hydraulic jump length on a gradual expansion basin with the rough bed were significantly smaller than that of the classical hydraulic jumps in a rectangular basin with smooth and rough bed. It should be mentioned that Pagliara and Palermo [23] and Felder and Chanson [24] took into consideration the effect of air concentration, bed roughness and channel slope on both sequent depth ratio and other lengths of HJs occurring on rough beds.

A numerical simulation of jump on smooth beds in the rectangular channels has been studied by many researchers. Gharangik and Chaudhry [25] investigated a hydraulic jump by a numerical model. They applied the Boussinesq equations to simulate both the sub and supercritical flows and a hydraulic jump in a rectangular channel having a small bed slope. The numerical study of hydraulic jump on a smooth bed has also been carried out by Zhao et al. [26]. The governing equations are the continuity and momentum for incompressible flow and based on the 2-dimensional k- $\varepsilon$ turbulence model. They used the volume of fluid (VOF) and the scale turbulence model to predict water surface location and horizontal velocity. Sarker and Rhodes [27] studied hydraulic jump on a smooth bed by physical and numerical methods. They used the Re-Normalization Group (RNG) and $k-\varepsilon$ turbulence models in combination with the VOF method for free surface modeling. There was a good agreement between the 2-dimensional computational fluid dynamics (CFD) solution and the physical measurements. Gonzalez and Bombardelli [28] simulated a hydraulic jump on a smooth bed using $k-\varepsilon$ and Large Eddy Simulation (LES) turbulence models. The simulated results were compared with observations of mean flow and turbulence in hydraulic jumps by Liu et al. [29]. Velioglu et al. [30] studied the effects of strip roughness elements on the characteristics of hydraulic jumps such as conjugate depth ratio, jump length and energy dissipation, experimentally and numerically using Flow 3D model. They found that the strip roughness elements have significant effects on the hydraulic jump characteristics. The tail water depth reduction compared to classical jump is $18-20 \%$. The length of the hydraulic jump is reduced about by $20-25 \%$. This type of roughness elements induces 2-3\% more energy dissipation than that of a classical hydraulic jump. Abbaspour et al. [31] performed numerical simulation of hydraulic jump on a corrugated bed using both standard $\mathrm{k}-\varepsilon$ and RNG models. They used the VOF method for free surface. Their results showed that k- $\varepsilon$ turbulent model and VOF method were suitable for predicting the water surface in the jump on a corrugated bed and the relative error of predicted water surface profiles and measured value were in the range of $1 \%-8.6 \%$. Bayon et al. [32] evaluated the performance of the FLOW-3D and Open FOAM models for simulation of the hydraulic jump in low Reynolds numbers. Comparison of numerical and experimental results showed a good agreement for sequent depth ratio and length of the hydraulic jump for both models. Recently, Viti et al. [33] have presented a literature review on the recent results and future outlook of the numerical simulation of hydraulic jumps.

In addition, the effects of the air concentration on the hydraulic jump characteristics have been studied. Pagliara and Palermo [23] showed that in a two-phase flow (water and entrained air), locating the water surface is problematic and an equivalent flow depth $\left(d_{e}\right)$ is commonly used. The depth de represents the normal distance from the channel invert reference (effective top ET) to an elevation where the air concentration reaches $90 \%$. Similarly, Felder and Chanson [24] noticed that the upstream flow was rough and aerated for several flow conditions affecting the accuracy of the flow depth recording, and that the upstream depth, $d_{1}$, defined in terms of the equivalent clear-water depth, $d$, determined based upon void fraction measurements.

Many previous studies have focused on the hydraulic jumps over smooth beds and few studies have investigated the effect of rough bed on the characteristics of the hydraulic jump numerically. Therefore, in this paper, important the hydraulic jump characteristics such as the water surface profile, jump and roller length, and velocity distribution were investigated based on a detailed comparison with an experimental study. Furthermore, this paper will answer some important questions about the ability of Flow-3D numerical model to simulate the hydraulic jump characteristics and how much the differences between the experimental data and numerical outputs. 


\section{Material and methods}

\subsection{Experimental data}

The experimental were conducted at the Water Research Center, Department of Irrigation and Reclamation Engineering (University of Tehran) in a metal-glass flume of rectangular cross section. The flume has the dimensions of $0.25 \mathrm{~m}$ width, $0.5 \mathrm{~m}$ depth, and $12 \mathrm{~m}$ length with a slope of 0.002 . The flume is equipped with a sluice gate at the entrance and discharge was measured by a triangular weir placed at the end of it.

The initial and secondary depths of the hydraulic jump were measured using a point gauge with a precision of $0.1 \mathrm{~mm}$. Longitudinal water surface profile of the hydraulic jump was determined by means of photographing and digiting using Grapher software (ver. 7.0.1870, Golden Software, Colorado 80401). In order to stabilize the hydraulic jump and form the initial depth, a crack valve was used at a distance of $17 \mathrm{~cm}$ downstream of the sliding valve, to adjust the secondary depth of the hydraulic jump. Fig. 1 illustrates the flow conditions and hydraulic jump characteristics. In addition, the effective parameters and the range of variations are presented in Fig. 2 and Table 1.

\subsection{Numerical modelling}

In the present research, hydraulic jump on a corrugated bed was numerically studied for different Froude numbers using the 2-phase flow theory. The water surface location was determined with the VOF method. RNG turbulent models were used to simulate the hydraulic jump on corrugated bed. Flow-3D is a CFD model which uses VOF method. Flow 3D (Ver. 11.2.0.16, Flow Science) model gives satisfactory results on free surface flows by solving the Reynoldsaveraged Navier-Stokes (RANS) equations over the computational domain [34]. For three-dimensional simulation of the flow in an incompressible state, this model solves the Reynolds-averaged Navier-Stokes (RANS) equations using a finite volume method on a grid domain. These equations in Cartesian coordinate system are as follows:

$$
\begin{aligned}
& V_{F} \frac{\partial \rho}{\partial t}+\frac{\partial\left(\rho u A_{x}\right)}{\partial x}+\frac{\partial\left(\rho u A_{y}\right)}{\partial y}+\frac{\partial\left(\rho u A_{z}\right)}{\partial z}=R_{S O R}+R_{D I F} \\
& \frac{\partial u}{\partial t}+\frac{1}{V_{F}}\left(u A_{x} \frac{\partial u}{\partial x}+v A_{y} \frac{\partial u}{\partial y}+w A_{z} \frac{\partial u}{\partial z}\right)=\frac{1}{\rho} \frac{\partial P}{\partial x}+G_{x}+f_{x} \\
& \frac{\partial v}{\partial t}+\frac{1}{V_{F}}\left(u A_{x} \frac{\partial u}{\partial x}+v A_{y} \frac{\partial u}{\partial y}+w A_{z} \frac{\partial u}{\partial z}\right)=\frac{1}{\rho} \frac{\partial P}{\partial y}+G_{y}+f_{y} \\
& \frac{\partial w}{\partial t}+\frac{1}{V_{F}}\left(u A_{x} \frac{\partial u}{\partial x}+v A_{y} \frac{\partial u}{\partial y}+w A_{z} \frac{\partial u}{\partial z}\right)=\frac{1}{\rho} \frac{\partial P}{\partial z}+G_{z}+f_{z}
\end{aligned}
$$

where, $u, v, w$ are velocity components; $A_{x}, A_{y}$, and $A_{z}$ are the flow areas, $G_{x}, G_{y}$, and $G_{z}$ are gravitational accelerations; $f_{x}, f_{y}$, and $f_{z}$ are accelerations due to the viscosity; $\rho$ is the fluid density; $R_{S O R}$ is the mass source; $R_{D I F}$ is the source of turbulent diffusion; $V_{F}$ is the flow volume and $P$ is the pressure. In all the simulations, the six-sided boundary

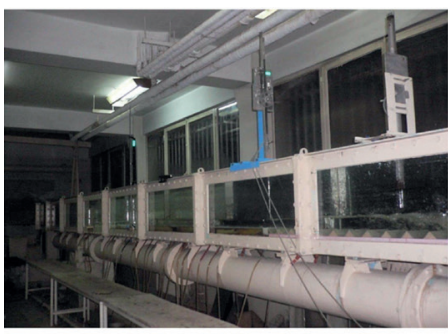

(a)

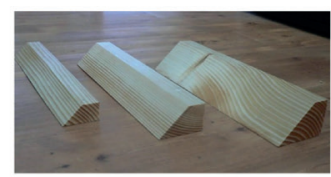

(b)
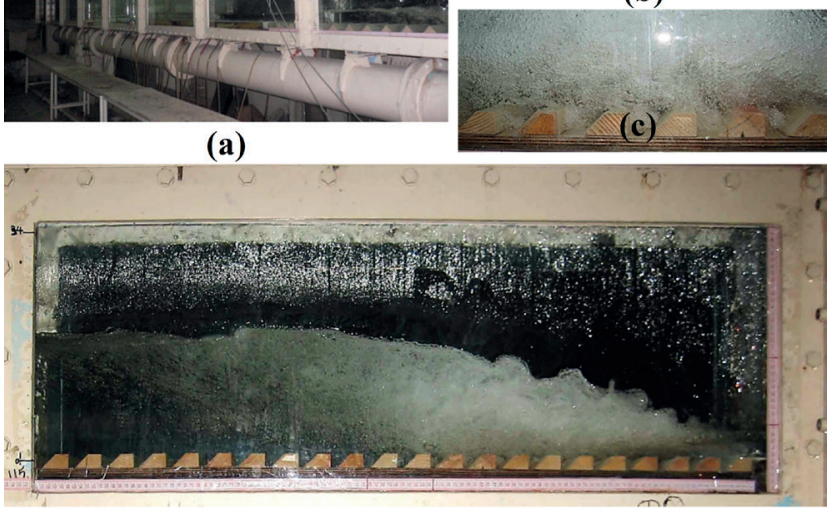

(d)

Fig. 1 (a) The view of the laboratory flume used for the experiments; (b) A view of the used roughness; and (c) and (d) A schematic view of the hydraulic jump formed downstream of the sluice gate [35]

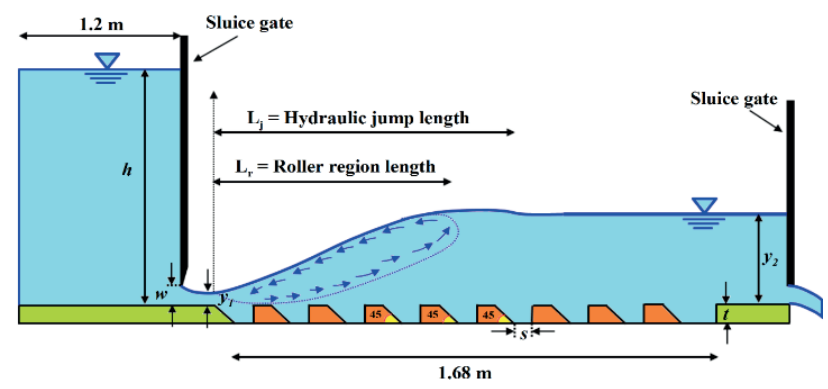

Fig. 2 The schematic view of formed hydraulic jump over the rough bed and its characteristics

Table 1 Studied Parameters and range of changes

\begin{tabular}{lcc}
\hline Effective Parameters & Symbol & Range of Variations \\
\hline Initial depth of the hydraulic jump & $y_{1}(\mathrm{~m})$ & $0.012-0.016$ \\
Sequent depth of the hydraulic jump & $y_{2}(\mathrm{~m})$ & $0.094-0.222$ \\
Hydraulic jump length & $L_{j}(\mathrm{~m})$ & $0.320-0.800$ \\
Roller region length & $L_{r}(\mathrm{~m})$ & $0.150-0.460$ \\
Flow Discharge & $Q\left(\mathrm{~m}^{3} / \mathrm{s}\right)$ & $0.006-0.015$ \\
$\begin{array}{l}\text { Initial Froude Number } \\
\text { Roughness Height }\end{array}$ & $F r_{1}(-)$ & $5.010-13.700$ \\
$\begin{array}{l}\text { The distance between two } \\
\text { roughnesses }\end{array}$ & $s(\mathrm{~m})$ & $0.020,0.030,0.040$ \\
\hline
\end{tabular}


conditions were introduced into the Flow 3D model: $X_{\text {min }}$ (upstream sluice face, the upstream depth was applied to the model at a distance of $1.2 \mathrm{~m}$ ), $X_{\max }$ (end of laboratory flume, tail-water depth was introduced as a downstream boundary condition). $Y_{\min }$ and $Y_{\max }$ (The left and right walls were introduced to the model as wall boundary condition). For $Z_{\min }$ and $Z_{\max }$, the wall and symmetry boundary conditions were used, respectively. After defining the experimental conditions to the numerical model, the model was run. Fig. 3 shows the output numerical simulation for different flow conditions.

\subsection{Verification using experimental data}

After obtaining the outputs of the numerical model for the water surface profile, the numerical results were compared with the experimental data of Ravar [35]. In this study, the water surface profile (initial and secondary depths of the hydraulic jump) was used for verification of the numerical model. It should be noted that the water surface profile was determined using the VOF method. Numerical simulations were calibrated with both discharge and water surface profiles. Fig. 4 shows a comparison between the experimental and numerical results of two parameters of discharge and secondary depth of the hydraulic jump, as well as the values of statistical indices of Mean Absolute Relative Error $\quad\left(\operatorname{MARE}=100 / n \sum_{i=1}^{n} \mid\left(Q_{i(\mathrm{exp})}-Q_{i(\text { call })}\right) / Q_{i \text { (exp) })}\right)$, Maximum Error $\left.\left(M E=\left[\operatorname{Max} \mid\left(Q_{i(\mathrm{exp})}-Q_{i(c a l)}\right) / Q_{i(\mathrm{exp})}\right)\right] \times 100\right)$, and Root Mean Squared Error $\left(R M S E=\left[1 / n \sum_{i=1}^{n}\left(Q_{i(\mathrm{exp})}-Q_{i(\mathrm{cal})}\right)^{2}\right]^{0.5}\right)$. These values show that the Flow3D model has a great ability to estimate the hydraulic parameters of the hydraulic jump over the rough beds.

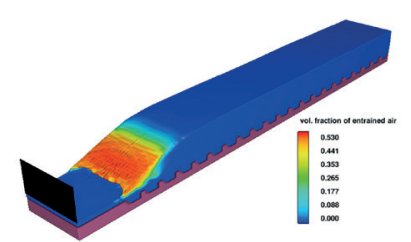

(a)

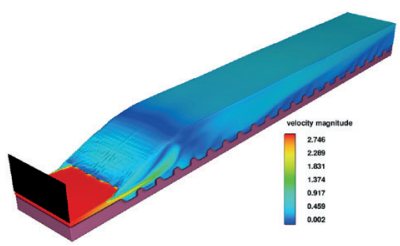

(b)

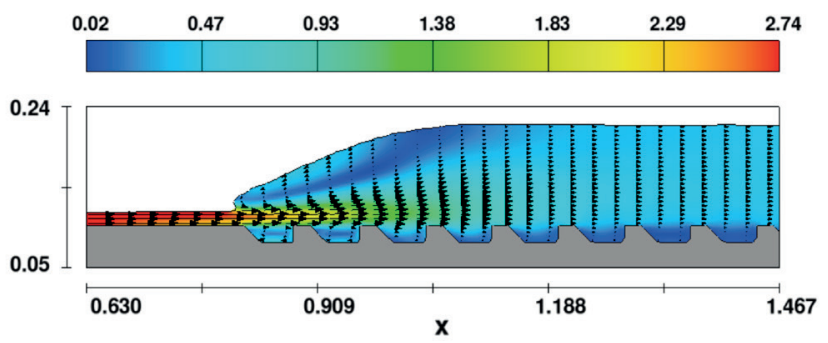

(c)

Fig. 3 The output numerical simulation for different flow conditions; (a) 3D variations of air concentration; (b) 3D variations of flow velocity; (c) Two-dimensional variations of flow velocity in different sections (a)
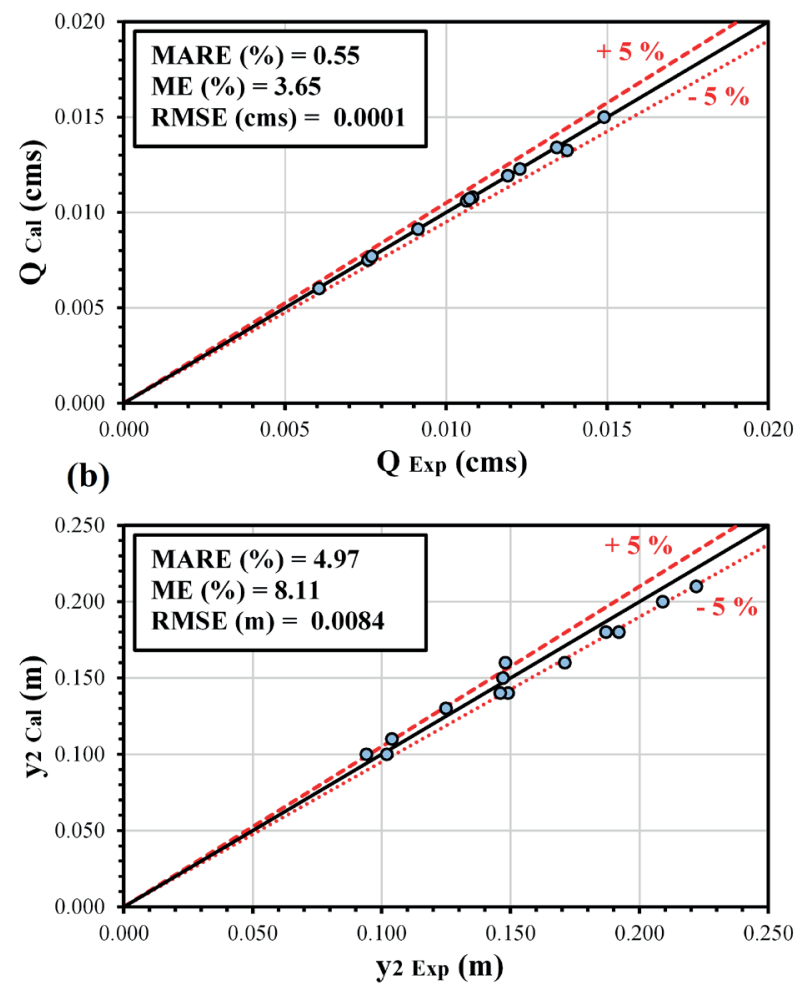

Fig. 4 (a) Comparison of experimental and numerical discharges;

(b) Comparison of experimental and numerical sequent depths

Different characteristics of hydraulic jump including the water surface profile, sequent depth ratio, the length of hydraulic jump, and velocity distributions over the rough bed with different arrangement and the results are summarized in the following (Table 2).

\section{Results}

\subsection{Water surface profile}

By analyzing the results of the model output, the water surface profiles were obtained for different tests are shown in Fig. 5. By plotting non-dimensional values of $\left(x / L_{j}\right)$ vs. $\left(y-y_{1}\right) /\left(y_{2}-y_{1}\right)$, the water surface profiles were obtained for different experiment (Fig. 6). According to this figure, the water surface profiles are similar in different conditions. In addition, the following relationship was obtained for dimensionless water surface profiles:

$\left(\frac{y-y_{1}}{y_{2}-y_{1}}\right)=\frac{\left(x / L_{j}\right)^{2.143}}{0.026+\left(x / L_{j}\right)^{2.143}}$,

where, $x$ and $y$ are the horizontal and vertical distances, $y_{1}$ and $y_{2}$ are the initial and secondary depths of the hydraulic jump and $L_{j}$ is the hydraulic jump's length. This relationship predict the dimensionless water surface profile with high accuracy $(\mathrm{MAE}=6.02 \%)$ 
Table 2 List of simulations performed in this study

\begin{tabular}{|c|c|c|c|c|c|c|c|c|c|c|c|c|c|}
\hline \multirow{2}{*}{ Run No. } & \multirow{2}{*}{$t(\mathrm{~m})$} & \multirow{2}{*}{$s(\mathrm{~m})$} & \multirow{2}{*}{$\underset{\left(\mathrm{m}^{3} / \mathrm{s}\right)}{Q}$} & \multicolumn{5}{|c|}{ Experimental } & \multicolumn{5}{|c|}{ Simulated } \\
\hline & & & & $F r_{1}$ & $y_{1}(\mathrm{~m})$ & $y_{2}(\mathrm{~m})$ & $F r(\mathrm{~m})$ & $L_{j}(\mathrm{~m})$ & $\mathrm{Fr}_{1}$ & $y_{1}(\mathrm{~m})$ & $y_{2}(\mathrm{~m})$ & $F r(\mathrm{~m})$ & $L_{j}(\mathrm{~m})$ \\
\hline 1 & & & 0.008 & 5.01 & 0.016 & 0.10 & 0.17 & 0.39 & 4.96 & 0.016 & 0.10 & 0.13 & 0.35 \\
\hline 2 & & & 0.011 & 7.04 & 0.016 & 0.15 & 0.28 & 0.55 & 7.01 & 0.016 & 0.15 & 0.23 & 0.50 \\
\hline 3 & 0.02 & 0.04 & 0.015 & 9.86 & 0.016 & 0.21 & 0.37 & 0.79 & 9.93 & 0.016 & 0.20 & 0.34 & 0.66 \\
\hline 4 & & & 0.006 & 6.03 & 0.012 & 0.09 & 0.15 & 0.38 & 5.99 & 0.012 & 0.10 & 0.18 & 0.32 \\
\hline 5 & & & 0.014 & 13.70 & 0.012 & 0.22 & 0.46 & 0.80 & 13.20 & 0.012 & 0.21 & 0.42 & 0.76 \\
\hline 6 & & & 0.008 & 5.09 & 0.016 & 0.10 & 0.16 & 0.32 & 5.10 & 0.016 & 0.11 & 0.13 & 0.27 \\
\hline 7 & 0.03 & 0.06 & 0.011 & 7.16 & 0.016 & 0.15 & 0.23 & 0.54 & 7.15 & 0.016 & 0.14 & 0.20 & 0.47 \\
\hline 8 & & & 0.013 & 8.89 & 0.016 & 0.19 & 0.31 & 0.67 & 8.87 & 0.016 & 0.18 & 0.28 & 0.61 \\
\hline 9 & & & 0.009 & 6.04 & 0.016 & 0.12 & 0.17 & 0.33 & 6.04 & 0.016 & 0.13 & 0.17 & 0.31 \\
\hline 10 & & & 0.011 & 7.10 & 0.016 & 0.15 & 0.20 & 0.36 & 7.09 & 0.016 & 0.16 & 0.21 & 0.31 \\
\hline 11 & 0.04 & 0.08 & 0.012 & 8.13 & 0.016 & 0.17 & 0.22 & 0.43 & 8.13 & 0.016 & 0.16 & 0.23 & 0.40 \\
\hline 12 & & & 0.009 & 9.09 & 0.012 & 0.15 & 0.23 & 0.54 & 9.09 & 0.012 & 0.14 & 0.23 & 0.49 \\
\hline 13 & & & 0.012 & 11.87 & 0.012 & 0.19 & 0.28 & 0.62 & 11.88 & 0.012 & 0.18 & 0.26 & 0.56 \\
\hline
\end{tabular}
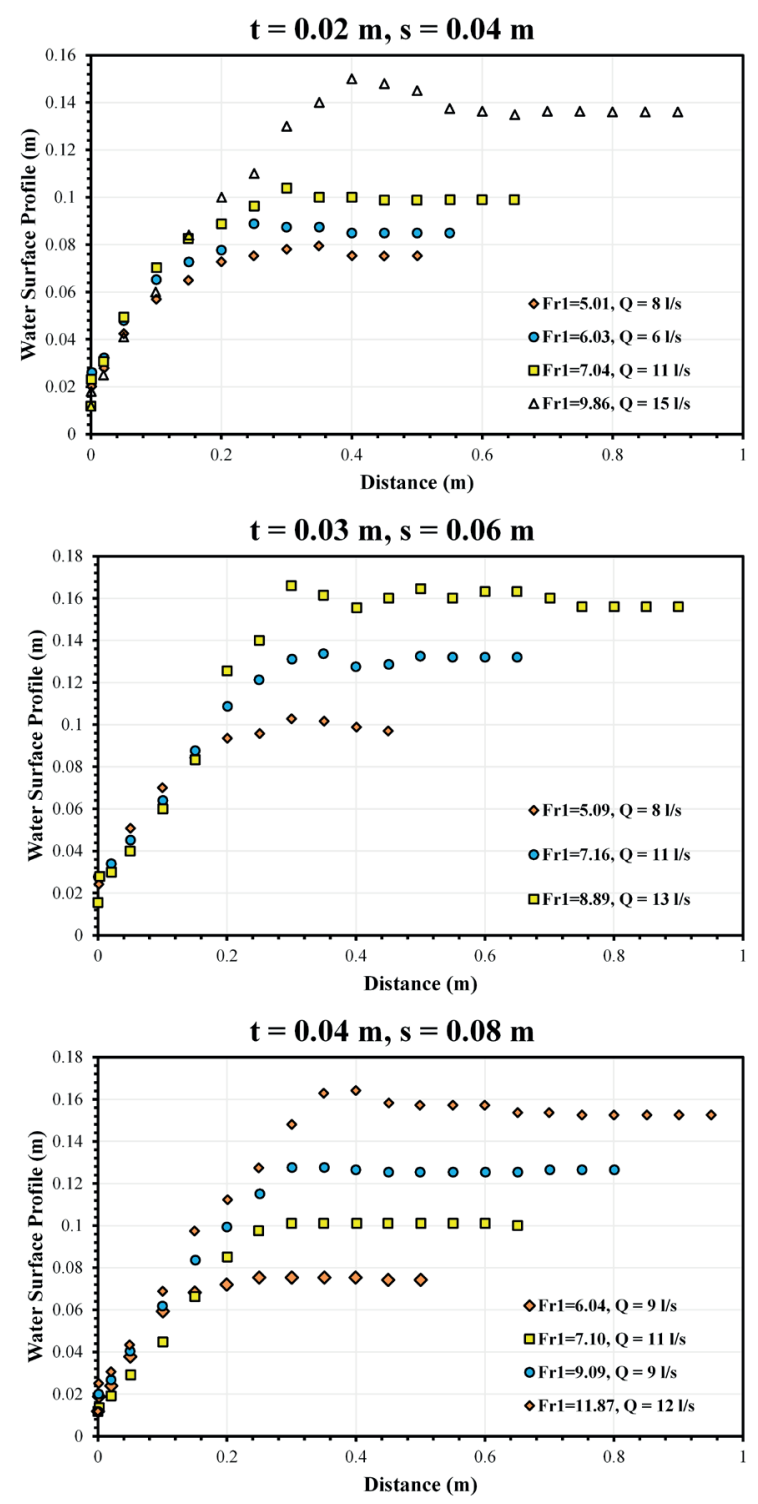

Fig. 5 The water surface profiles obtained for different tests

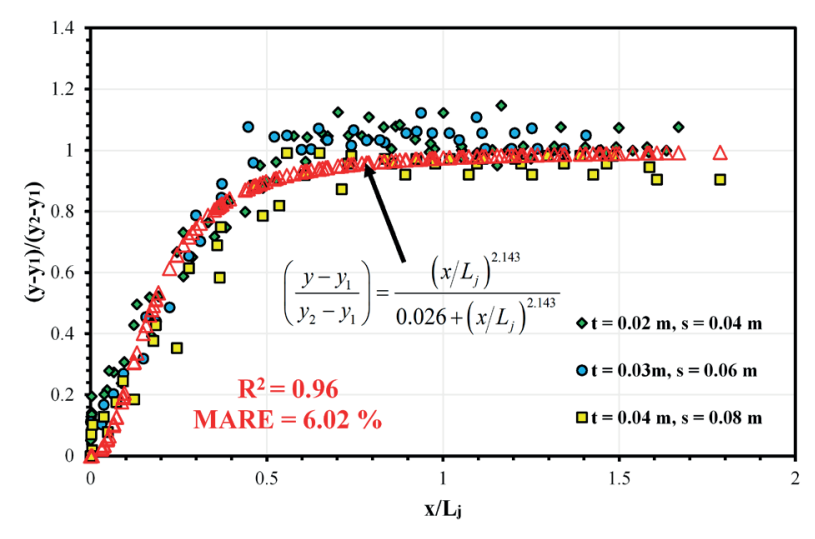

Fig. 6 Dimensionless water surface profiles over the rough bed for all simulations

\subsection{Sequent depth ratio}

Fig. 7(a) shows the values of $y_{2} / y_{1}$ against $F r_{1}$. A comparison between numerical and experimental measurements of the sequent depth ratio over the rough bed and the data obtained from the Belanger equation (Belanger [36]; Chanson [37]) is shown in Fig. 6(b). As can be seen, the simulation and theoretical results are compatible with each other, and the existing differences can be applied to the errors in the numerical solution, and the hypotheses refer to the Belanger's equation. The mean error between the numerical and experimental simulation results is about $4.8 \%$. Existing differences can be attributed to the errors in the numerical simulation and the hypotheses considered in the Belanger's equation.

In general, the results showed that the height and distance of roughness reduce the sequent depth ratio for all Froude numbers and this trend is intensified by increasing the Froude number. In other words, reduction of the boundary layer thickness will further increase the effect of 
a)
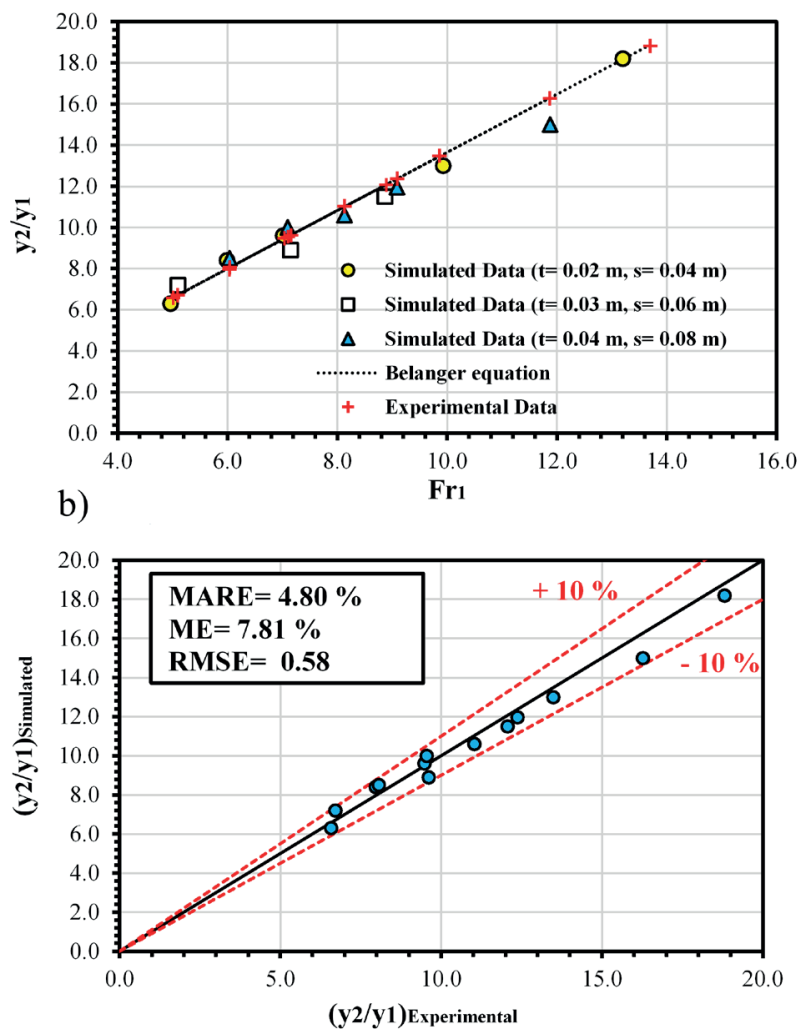

Fig. 7 (a) Changes in the sequent depth ratios vs. initial Froude number; (b) Comparison of experimental and numerical sequent depth ratios

roughness and intensify reduction of the secondary depth ratio. This slight decrease can also be attributed to the increase in the vortex moving between the roughnesses, which increases with the increasing the Froude number.

\subsection{The hydraulic jump length}

Hydraulic jump length is defined as the distance between the two cross-sections with the conjugate depths. In the experimental study, the length of the hydraulic jump is equal to the distance between the beginning of the jump and a point where the water surface fluctuations fades. Similarly, in the results of numerical simulations, the same method was used to determine the length of the hydraulic jump. Fig. 8(a) shows the experimental data and numerical results for relative length of the hydraulic jump $\left(L_{j} / y_{1}\right)$ vs. the Froude numbers $\left(F r_{1}\right)$ on the rough bed. In addition, Fig. 8(b) shows a comparison between the experimental data and numerical results for relative length of the hydraulic jump. According to these figures, the changes in the experimental and numerical results are in a good agreement $($ MARE $=10.85 \%$ ). It should be noted that numerical model have underestimated the hydraulic jump length compared to experimental conditions. a)

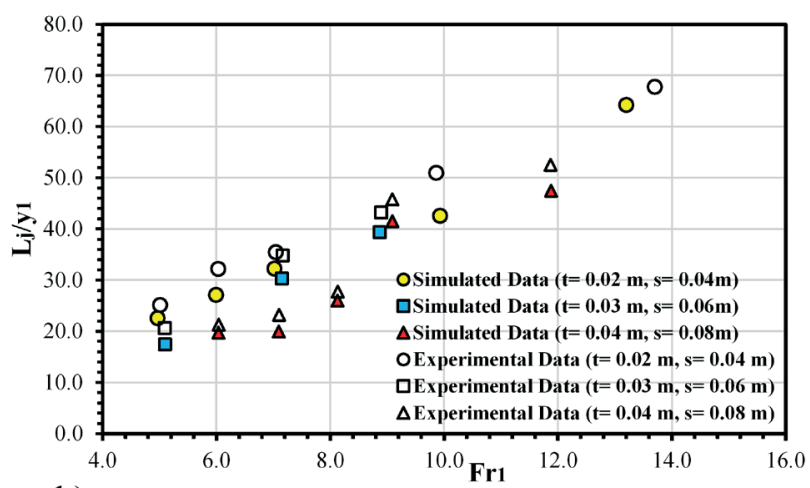

b)

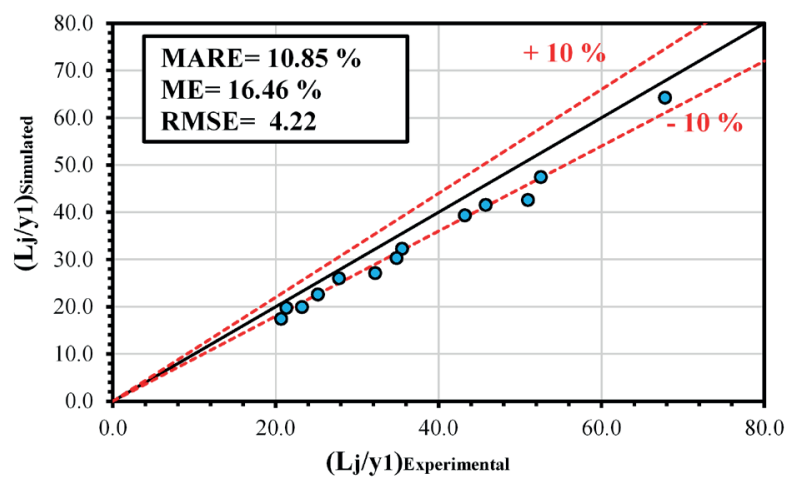

Fig. 8 (a) Variation of relative length of hydraulic jump versus initial Froude number; (b) Comparison of numerical and experimental relative length of hydraulic jump

In addition, with increasing the height and distance between roughnesses, the length of the hydraulic jump decreased significantly. Increase of the Froude number may intensify this trend, so that for the maximum Froude numbers the length of the hydraulic jump decreased about $28 \%$. This reduction is due to the formation of vortex flow, and its effects may appear as a reduction in the pressure and an increase in the mixing the air bubbles.

\subsection{Roller length}

Fig. 9(a) shows the relative roller length of the hydraulic jump $\left(L_{r} / y_{1}\right)$ against $F r_{1}$ in different the heights and distances between roughnesses. According to Fig. 9(b), it can be seen that the numerical model is well able to predict the relative roller length with MARE $=10.59 \%$. In this study, the roller length was measured similar to the length of the hydraulic jump. The results showed that the reduction in the roller length depends mainly on the space of the roughnesses, in which the vortex flow forms. For this reason, with increasing the height and distance between the roughnesses, the roller length decreases by about $36 \%$. In general, as mentioned by Pagliara and Palermo [23] and Felder and Chanson [24], the hydraulic jump characteristics are 
a)

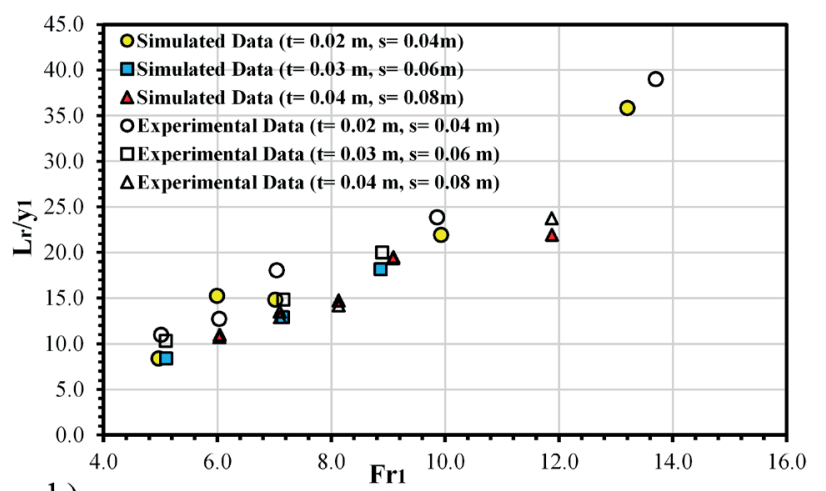

b)

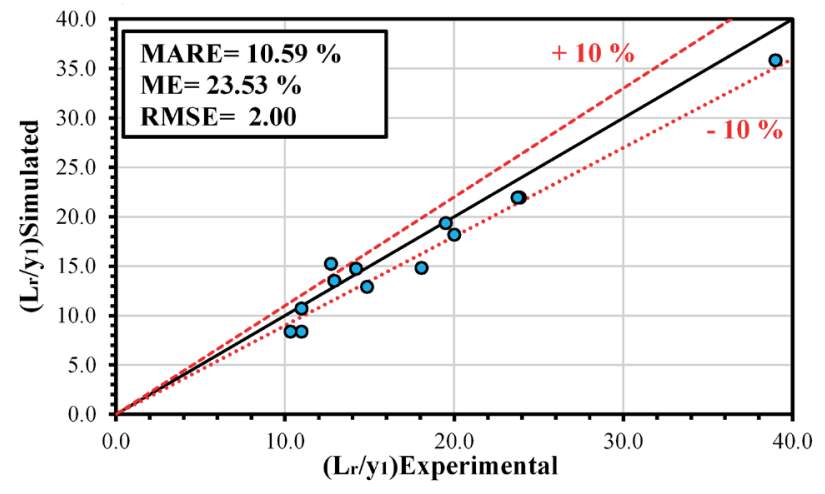

Fig. 9 (a) Variation of roller length of hydraulic jump versus initial Froude number; (b) Comparison of numerical and experimental roller length of hydraulic jump

deeply affected by the air concentration. This is a fundamental issue, having a significant impact on the generalizability and correctness of the results. This can also be considered as an important reason for observing errors between experimental and simulated results.

\subsection{Velocity distribution}

In the experimental study, the velocity distributions have not been measured. However, according to the calibration of the numerical model based on experimental data (water surface profiles), one can rely on other outputs of numerical model. Typical velocity distribution in hydraulic jump is shown in Fig. 10. In this figure, the parameter $b$ is the value of $y$ at which $u=0.5 u_{\max }$ and $\delta$ represents the position of maximum velocity

In this study, the velocity distribution was simulated at 4 sections during the hydraulic jump. These sections are different for each arrangement of roughness (due to the difference in the length of the hydraulic jump in each mode). Furthermore, these sections were measured on top of the roughness elements. The velocity distribution in hydraulic jumps at different distances from the beginning of the hydraulic jump and different Froude numbers are shown

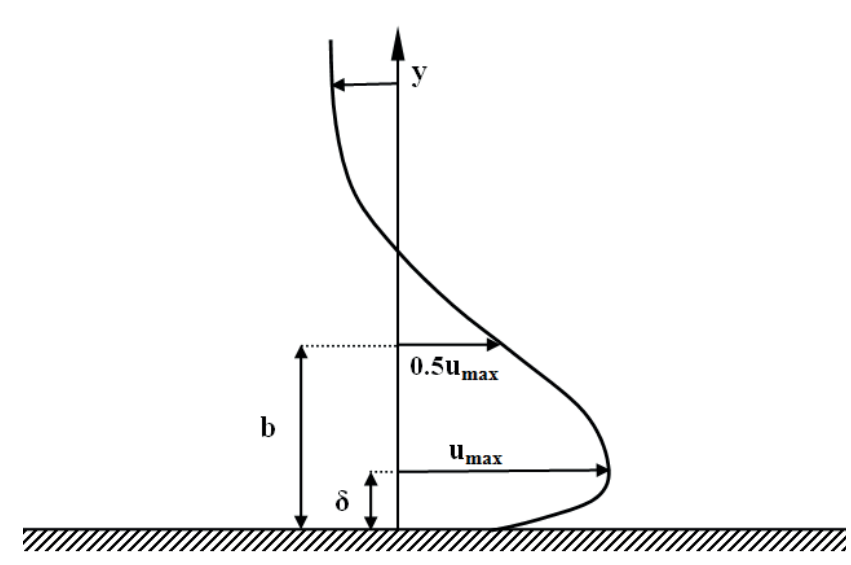

Fig. 10 Typical velocity distribution in hydraulic jump [1]

in Figs. 11 to 13 In these figures, $x$ represents the distance from the beginning of the hydraulic jump. Since the shear stress decreases with increasing distance from the beginning of the hydraulic jump and the flow depth increases, the maximum velocity at each section will decrease along the hydraulic jump.

The velocity distribution in the hydraulic jumps is usually shown by plotting the ration of $y / b$ versus $u / u_{\max }$. As can be seen in Fig. 14, the velocity distributions in hydraulic jumps is the same for all the Froude numbers. In addition, increasing the distance and the height of the roughness will reduce the velocities near the bed and increase the gradient of the velocity distribution near the bed. In other words, on the rough beds, the maximum velocity will occur in a higher distance from the bed than that of the smooth beds, indicating the increase in the thickness of the inner layer of the horizontal velocity distribution.

Fig. 15 presents the dimensionless velocity distribution in hydraulic jump for all the rough beds. As can be seen, the velocity distributions follow a similar trend for all conditions, and the change in height and distance does not significantly affect the velocity distributions.

The ratio $b / y_{1}$ are plotted against the ratio of $x / y_{1}$ (Fig. 16). The parameter $b$ represents the value of $y$ at which $u=0.5 u_{\max }$. As can be seen, by increasing the distance from the beginning of the hydraulic jump, the parameter $b$ increases. This shows that with increasing distance from the beginning of the hydraulic jump, the position of maximum velocity (i.e., the thickness of the inner layer of the horizontal velocity distribution) increases. It should be noted that the height and distance of roughness have no significant effect on this parameter.

The following equation was also developed to estimate the relative position of maximum velocity $\left(b / y_{1}\right)$ as a function of $\left(x / y_{1}\right)$ : 

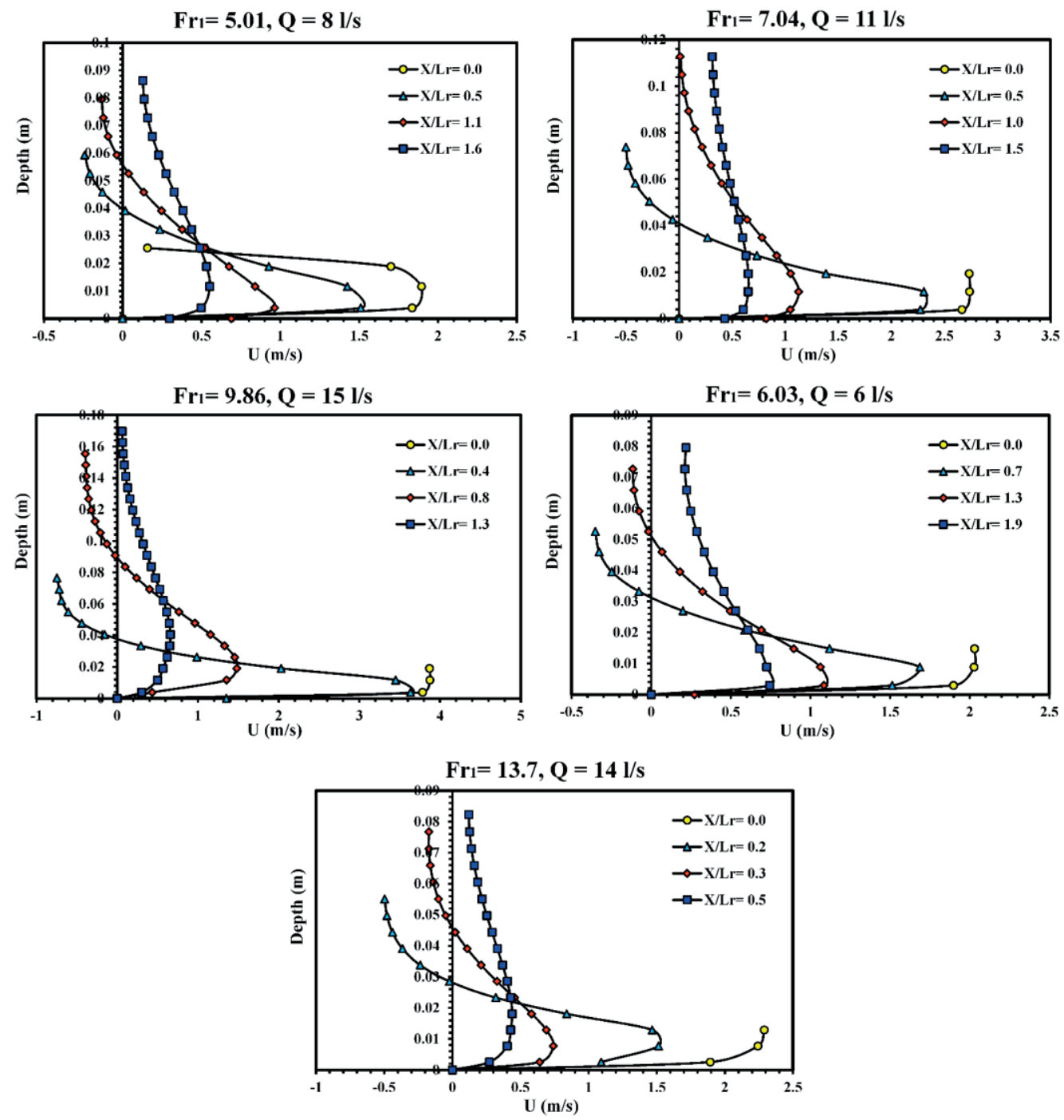

Fig. 11 Velocity distribution at different distances from the beginning of the hydraulic jump for different Froude numbers and different flow discharges $(t=0.02 \mathrm{~m}, s=0.04 \mathrm{~m})$

$$
\frac{b}{y_{1}}=\frac{25.88}{\left(1+28.91 \times 10^{\left.-0.08\left(\frac{x}{y_{1}}\right)\right)}\right.},
$$

in which, $x$ is the desired distance from the beginning of the hydraulic jump.

\section{Conclusions}

In this study, the characteristics of hydraulic jump including water surface profile, sequent depth ratio, hydraulic jump length, roller length and velocity distribution over rough beds with trapezoid blocks were numerically investigated using Flow-3D model, which it was not completely considered in the previous studies. In order to simulate the flow turbulence and hydraulic jump formed over the trapezoid blocks, a RNG method. The results of this study are briefly summarized as follows:
- The water surface profiles of the hydraulic jump are similar for different tests. This result was also obtained in the experimental study.

- The results showed that the value of MARE between the simulated and measured sequent depth ratios are $4.8 \%$. The results also showed that the height and distance of roughness slightly reduced the sequent depth ratios for all Froude numbers.

- The value of MARE between the experimental and the numerical results for the hydraulic jump length was about $10.85 \%$. This difference can be due to the difference in the criterion used for measuring the length of the hydraulic jump. In addition, with increasing the height and distance between roughnesses, the lengths of the hydraulic jump decreased significantly. 

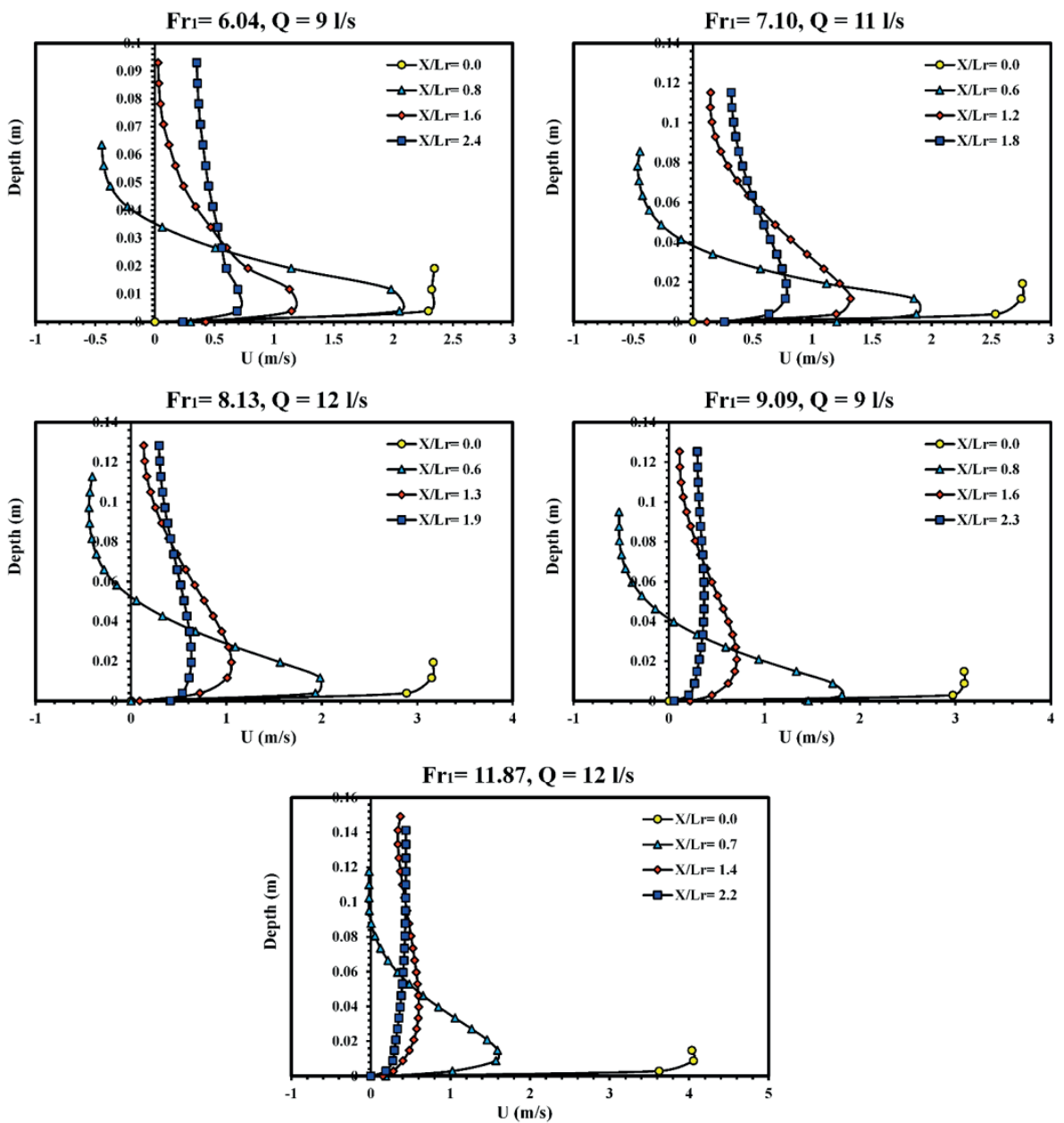

Fig. 12 Velocity distribution at different distances from the beginning of the hydraulic jump for different Froude numbers and different flow discharges $(t=0.04 \mathrm{~m}, s=0.08 \mathrm{~m})$
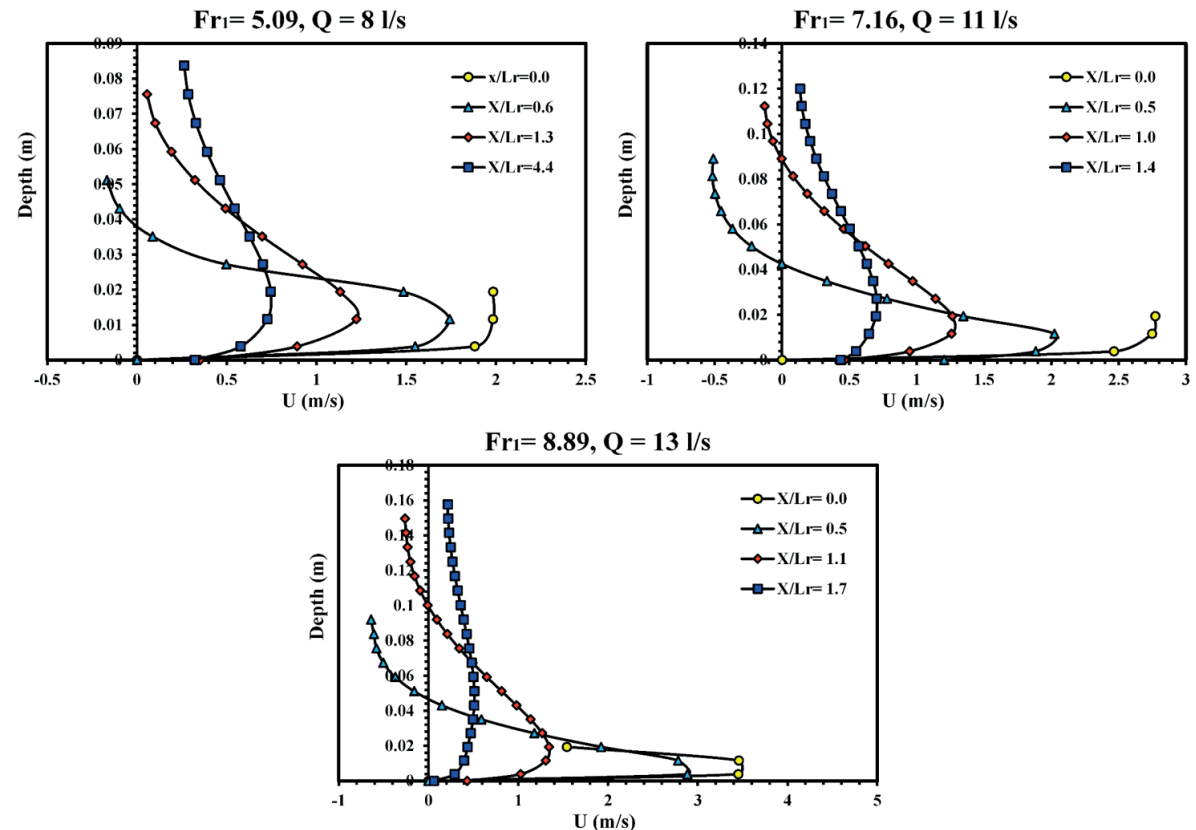

Fig. 13 Velocity distribution at different distances from the beginning of the hydraulic jump for different Froude numbers and different flow discharges $(t=0.03 \mathrm{~m}, s=0.06 \mathrm{~m})$ 


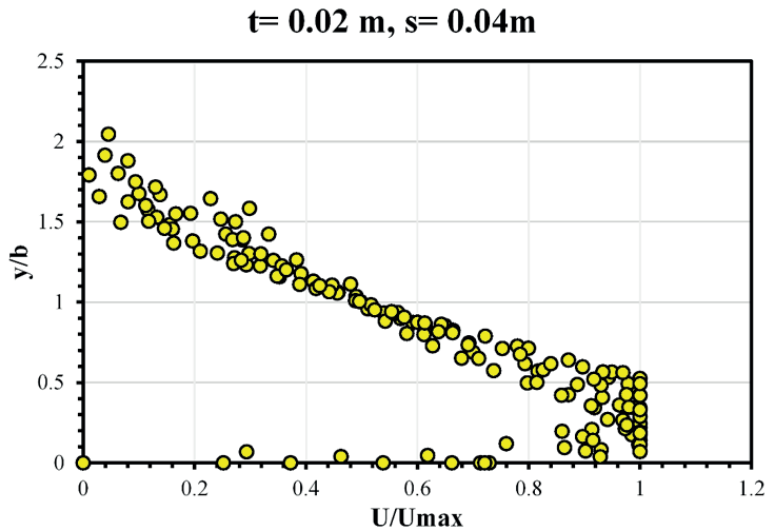

(a)

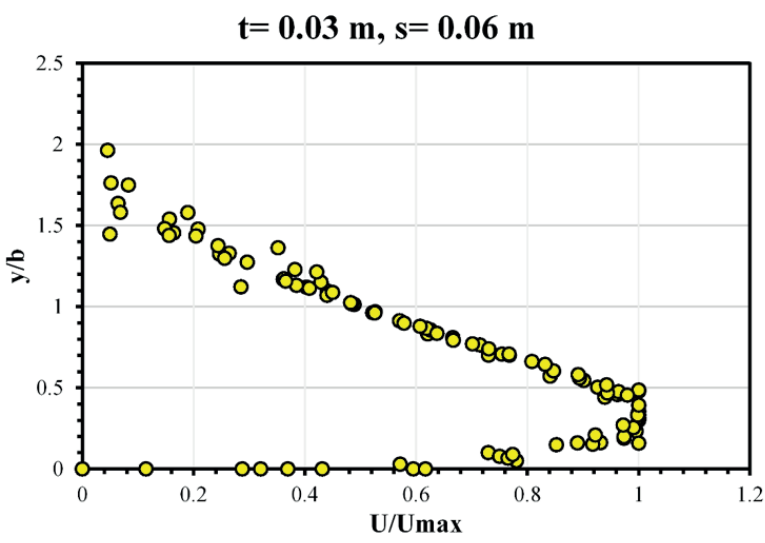

(b)

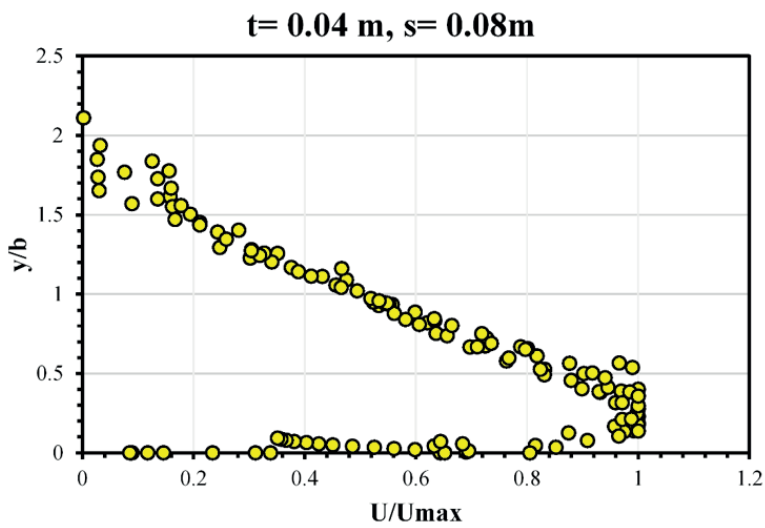

(c)

Fig. 14 Comparison of the dimensionless velocity distribution in rough beds

\section{References}

[1] Omid, M. H., Nasrabadi, M., Farhoudi, J. "Suspended sediment effects on hydraulic jump characteristics", Water Management, 164(2), pp. 91-101, 2011.

https://doi.org/10.1680/wama.1000019

[2] Thompson, P., Kilgore, R. "Hydraulic jump. Hydraulic Engineering Series", BSc Thesis, University of Lagos, 2006.

[3] Rajaratnam, N. "The Hydraulic Jump as a Wall Jet", Journal of the Hydraulics Devision, 91(5), pp. 107-132, 1965.
- By analyzing the velocity data during the hydraulic jump, it was found that the maximum velocity at each section will decrease along the hydraulic jump.

- Non-dimensional velocity distribution in the hydraulic jumps is the same for all Froude numbers. In addition, increasing the distance and the height of the roughness will slow down the velocity near the bed and increase the gradient of the velocity distribution near the bed.

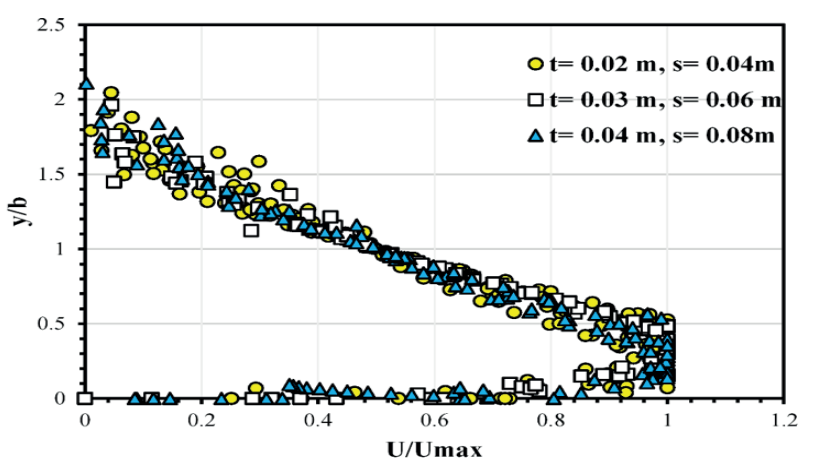

Fig. 15 Dimensionless velocity distribution in the hydraulic jump for different Froude numbers 280 in rough beds

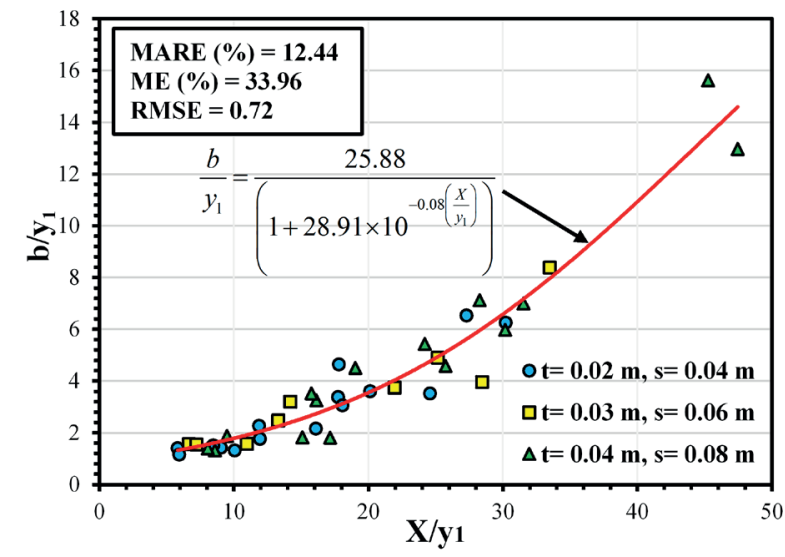

Fig. 16 The ratio $b / y_{1}$ vs. $x / y_{1}$ for different rough beds

[4] Launder, B. E., Rodi, W. "The turbulent wall jet", Progress in Aerospace Sciences, 19, pp. 81-128, 1979. https://doi.org/10.1016/0376-0421(79)90002-2

[5] Launder, B. E., Rodi, W. "The turbulent wall jet measurements and modeling", Annual Review of Fluid Mechanics, 15, pp. 429459, 1983. https://doi.org/10.1146/annurev.fl.15.010183.002241

[6] McCorquodale, J. A. "Hydraulic jumps and internal flows", In: Cheremisinoff, N. P. (ed) Encyclopedia of Fluid Mechanics, 2, Golf Publishing, Houston, TX, USA, 1986, pp. 120-173. 
[7] Hager, W. H. "Various Aspects of Stilling Basins", In: Energy Dissipaters and Hydraulic Jump, Springer, Dordrecht, Netherlands, 1992, pp. 185-212. https://doi.org/10.1007/978-94-015-8048-9_12

[8] Azimi, H., Shabanlou, S., Kardar, S. "Characteristics of Hydraulic Jump in U-Shaped Channels", Arabian Journal for Science and Engineering, 42, pp. 3751-3760, 2017. https://doi.org/10.1007/s13369-017-2503-5

[9] Khan, S. A. "An Analytical Analysis of Hydraulic Jump in Triangular Channel: A Proposed Model", Journal of The Institution of Engineers (India): Series A, 94, pp. 83-87, 2013. https://doi.org/10.1007/s40030-013-0046-7

[10] Mortazavi, M., Le Chenadec, V., Moin, P. Mani, A. "Direct numerical simulation of a turbulent hydraulic jump: turbulence statistics and air entrainment", Journal of Fluid Mechanics, 797, pp. 60-94, 2016. https://doi.org/10.1017/jfm.2016.230

[11] De Padova, D., F., Mossa, M., Sibilla, S. "SPH numerical investigation of the characteristics of an oscillating hydraulic jump at an abrupt drop", Journal of Hydrodynamics, 30, pp. 106-113, 2018. https://doi.org/10.1007/s42241-018-0011-z

[12] Rajaratnam, N. "Hydraulic jumps on rough beds", Transactions of the Engineering Institute of Canada, 11(A-2), pp. 1-8, 1968.

[13] Hughes, W. C., Flack, J. E. "Hydraulic Jump Properties Over a Rough Bed", Journal of Hydraulic Engineering, 110(12), pp. 17551771, 1984.

https://doi.org/10.1061/(ASCE)0733-9429(1984)110:12(1755)

[14] Hager, W. H. "Classical Hydraulic Jump", In: Energy dissipators and hydraulic jump, Springer, Dordrecht, Netherlands, 2013, pp. 5-40. https://doi.org/10.1007/978-94-015-8048-9 2

[15] Pourabdollah, N., Heidarpour, M., Koupai, J. A. "An Experimental and Analytical Study of a Hydraulic Jump Over a Rough Bed with an Adverse Slope and a Positive Step", Iranian Journal of Science and Technology, Transactions of Civil Engineering, 43, pp. 551561, 2019.

https://doi.org/10.1007/s40996-018-00230-2

[16] Mohamed Ali, H. S. "Effect of Roughened-Bed Stilling Basin on Length of Rectangular Hydraulic Jump", Journal of Hydraulic Engineering, 117(1), pp. 83-93, 1991 https://doi.org/10.1061/(ASCE)0733-9429(1991)117:1(83)

[17] Ead, S., Rajaratnam, N., Katopodis, C., Ade, F. "Turbulent OpenChannel Flow in Circular Corrugated Culverts", Journal of Hydraulic Engineering, 126(10), pp. 750-757, 2000 https://doi.org/10.1061/(ASCE)0733-9429(2000)126:10(750)

[18] Tokyay, N. D. "Effect of Channel Bed Corrugations on Hydraulic Jumps", In: World Water and Environmental Resources Congress 2005 "Impacts of Global Climate Change", Anchorage, AK, USA, 2005, pp. 3703-3712. https://doi.org/10.1061/40792(173)408

[19] Izadjoo, F., Shafai-Bejestan, M. "Corrugated Bed Hydraulic Jump Stilling Basin", Journal of Applied Sciences, 7(8), pp. 1164-1169, 2007. https://doi.org/10.3923/jas.2007.1164.1169

[20] Ead, S., Elsebaie, I. "Effect of bed corrugations on the characteristics of a hydraulic jump", Civil Engineering Research Magazine, 31, pp. 238-251, 2009.
[21] Carollo, F. G., Ferro, V., Pampalone, V. "Hydraulic Jumps on Rough Beds", Journal of Hydraulic Engineering, 133(9), pp. 989-999, 2007.

https://doi.org/10.1061/(ASCE)0733-9429(2007)133:9(989)

[22] Hassanpour, N., Hosseinzadeh Dalir, A., Farsadizadeh, D., Gualtieri, C. "An Experimental Study of Hydraulic Jump in a Gradually Expanding Rectangular Stilling Basin with Roughened Bed", Water, 9(12), pp. 945-968, 2017. https://doi.org/10.3390/w9120945

[23] Pagliara, S., Palermo, M. "Hydraulic jumps on rough and smooth beds: aggregate approach for horizontal and adverse-sloped beds", Journal of Hydraulic Research, 53(2), pp. 243-252, 2015. https://doi.org/10.1080/00221686.2015.1017778

[24] Felder, S., Chanson, H. "Air-Water Flow Patterns of Hydraulic Jumps on Uniform Beds Macro roughness", Journal of Hydraulic Engineering, 144(3), pp. 1-12, 2018 https://doi.org/10.1061/(ASCE)HY.1943-7900.0001402

[25] Gharangik, A. M., Chaudhry, M. H. "Numerical Simulation of Hydraulic Jump", Journal of Hydraulic Engineering, 117(9), pp. 1195-1211, 1991. https://doi.org/10.1061/(ASCE)0733-9429(1991)117:9(1195)

[26] Zhao, Q., Misra, S. K., Svendsen, I. A., Kirby, J. T. "Numerical study of a turbulent hydraulic jump", presented at the 17th ASCE Engineering Mechanics Conference, Newark, DE, USA, June, 13-16, 2004

[27] Sarker, M. A., Rhodes, D. G. "Physical Modelling and CFD Applied to Hydraulic Jump", In: 29th IAHR World Congress "21st Century: The New Era For Hydraulic Research", Beijing, China, 2001, pp. 525-530.

[28] Gonzalez, A., Bombardelli, F. "Two-phase-flow theoretical and numerical models for hydraulic jumps, including air entrainment", In: 31th IAHR World Congress "Water Engineering for the FutureChoices and Challenges", Seoul, South Korea, 2005, pp. 16-21. https://doi.org/10.3390/w11010028

[29] Liu, M., Rajaratnam, N., Zhu, D. Z. "Turbulence Structure of Hydraulic Jumps of Low Froude Numbers", Journal of Hydraulic Engineering, 130(6), pp. 511-520, 2004. https://doi.org/10.1061/(ASCE)0733-9429(2004)130:6(511)

[30] Velioglu, D., Tokyay, N. D., Dincer, A. "A numerical and experimental study on the characteristics of hydraulic jumps on rough beds", In: E-proceedings of the 36th IAHR World Congress, Hague, Netherlands, June, 28-July, 3, 2015. (online) Available at: https://pdfs.semanticscholar.org/b957/23b3c5082f172de622dcaee9f417923557ba.pdf [Accessed: 10 February 2020]

[31] Abbaspour, A., Farsadizadeh, D., Hosseinzadeh Dalir, A., Sadraddini, A. A. "Numerical study of hydraulic jumps on corrugated beds using turbulence models", Turkish Journal of Engineering and Environmental Sciences, 33, pp. 61-72, 2009. https://doi.org/10.3906/muh-0901-7

[32] Bayon, A., Valero, D., García-Bartual, R., Vallés-Morán, F. J., López-Jiménez, P. A. "Performance assessment of Open FOAM and FLOW-3D in the numerical modeling of a low Reynolds number hydraulic jump", Environmental Modelling and Software, 80, pp. 322-335, 2016

https://doi.org/10.1016/j.envsoft.2016.02.018 
[33] Viti, N., Valero, D., Gualtieri, C. "Numerical Simulation of Hydraulic Jumps. Part 2: Recent Results and Future Outlook", Water, 11(1), pp. $28-45,2019$.

https://doi.org/10.3390/w11010028

[34] Flow Science "FLOW-3D V9.3 User's Manual, Volume 1" (version 9.3) [computer program] Available at: file:///C:/Users/user/ Downloads/epdf.pub_flow-3d-v93-user-manual-volume-1.pdf [Accessed: 10 February 2020]

[35] Ravar, Z. "Effect of Arrangement and Height of Trapezoidal Blocks on Hydraulic Jump Characteristics", MS Thesis, University of Tehran, 2010.
[36] Belanger, J. B. C. J. "Essai sur la solution numerique de quelques problemes relatifs au mouvement permanent des eaux courantes" (Test on the numerical solution of some problems relating to the permanent movement of running waters), Kessinger Publishing, Whitefish, MT, USA, 1828. (in French)

[37] Chanson, H. "Development of the Bélanger equation and backwater equation by Jean-Baptiste Bélanger (1828)", Journal of Hydraulic Engineering, 135(3), pp. 159-163, 2009.

https://doi.org/10.1061/(ASCE)0733-9429(2009)135:3(159) 